\title{
Inter-identity amnesia in dissociative identity disorder: a simulated memory impairment?
}

Citation for published version (APA):

Huntjens, R. J., Peters, M. L., Woertman, L., Bovenschen, L. M., Martin, R. C., \& Postma, A. (2006). Interidentity amnesia in dissociative identity disorder: a simulated memory impairment? Psychological Medicine, 36, 857-63. https://doi.org/10.1017/S0033291706007100

Document status and date:

Published: 01/01/2006

DOI:

10.1017/S0033291706007100

Document Version:

Publisher's PDF, also known as Version of record

Document license:

Taverne

Please check the document version of this publication:

- A submitted manuscript is the version of the article upon submission and before peer-review. There can be important differences between the submitted version and the official published version of record.

People interested in the research are advised to contact the author for the final version of the publication, or visit the DOI to the publisher's website.

- The final author version and the galley proof are versions of the publication after peer review.

- The final published version features the final layout of the paper including the volume, issue and page numbers.

Link to publication

\footnotetext{
General rights rights.

- You may freely distribute the URL identifying the publication in the public portal. please follow below link for the End User Agreement:

www.umlib.nl/taverne-license

Take down policy

If you believe that this document breaches copyright please contact us at:

repository@maastrichtuniversity.nl

providing details and we will investigate your claim.
}

Copyright and moral rights for the publications made accessible in the public portal are retained by the authors and/or other copyright owners and it is a condition of accessing publications that users recognise and abide by the legal requirements associated with these

- Users may download and print one copy of any publication from the public portal for the purpose of private study or research.

- You may not further distribute the material or use it for any profit-making activity or commercial gain

If the publication is distributed under the terms of Article $25 \mathrm{fa}$ of the Dutch Copyright Act, indicated by the "Taverne" license above, 


\title{
Inter-identity amnesia in dissociative identity disorder: a simulated memory impairment?
}

\author{
RAFAËLE J. C. HUNTJENS*, MADELON L. PETERS, LIESBETH WOERTMAN, \\ LOES M. BOVENSCHEN, ROY C. MARTIN AND ALBERT POSTMA \\ Department of Clinical Psychology, Utrecht University, Utrecht, The Netherlands
}

\begin{abstract}
Background. Although included in the current edition of the DSM, there does not seem to be consensus among mental health professionals regarding the diagnostic status and scientific validity of dissociative identity disorder (DID). This study was aimed at the detection of simulation of interidentity amnesia in DID.
\end{abstract}

Method. A sample of 22 DID patients was included, together with a matched control sample of subjects instructed to simulate inter-identity amnesia, a guessor group that had no knowledge of the stimulus material and a normal control group. A multiple-choice recognition test was included. The rate of incorrect answers was determined. Moreover, the specific simulation strategy used was examined by providing subjects with a range of choices that varied in extent of disagreement with the correct answer and determining whether plausible or implausible answer alternatives were selected.

Results. On the recognition test DID patients selected incorrect answers above chance like simulators. Patients thus seem to use their knowledge of the correct answer in determining their given answer. They were not characterized by a well-thought-out simulating behaviour style, as indicated by the differences in selection of specific answer alternatives found between patients and simulators.

Conclusions. DID patients were found not to be characterized by an actual memory retrieval inability, in contrast to their subjective reports. Instead, it is suggested that DID may more accurately be considered a disorder characterized by meta-memory problems, holding incorrect beliefs about their own memory functioning.

\section{INTRODUCTION}

Although included in the current edition of the Diagnostic and Statistical Manual of Mental Disorders (DSM), there does not seem to be consensus among mental health professionals regarding the diagnostic status and scientific validity of dissociative identity disorder (DID), as indicated by recent surveys in the USA (Pope et al. 1999), Canada (Lalonde et al. 2001), and Ireland (Dorahy \& Lewis, 2002). Partly responsible for this lack of consensus is the concern

* Address for correspondence: Dr R. J. C. Huntjens, Department of Clinical Psychology, Faculty of Social Sciences, Utrecht University, PO Box 80.140, 3508 TC Utrecht, The Netherlands. (Email: R.J.C.Huntjens@fss.uu.nl) that DID may be an iatrogenic disorder or is caused by the suggestive influence of media and culture on suggestible individuals (Spanos, 1996; Lilienfeld et al. 1999; Allen \& Movius, 2000). Given this concern, it is surprising that relatively little experimental work has yet been performed on the issue of symptom production and symptom exaggeration in DID.

The few studies that have looked at the issue of symptom feigning in DID focused on the simulation of inter-identity amnesia, i.e. one identity being amnesic for events experienced by other identities (Silberman et al. 1985; Eich et al. 1997; Allen \& Movius, 2000; Huntjens et al. 2002, 2003). In these studies, tasks were used on which it was unclear beforehand whether 
simulation would be possible. Control subjects who were instructed to simulate were then included to examine whether simulation was possible or impossible. The simulators were exposed to the same learning material as patients and then asked to simulate inter-identity amnesia. Simulators proved unsuccessful in simulating inter-identity amnesia in a study by Huntjens et al. (2002, 2003), leading the authors to conclude that the experimental tasks used were simulation-resistant. The simulators did prove successful in two other studies. In a study by Allen \& Movius (2000), two different recognition tasks were used in a sample of four DID patients. A comparison sample consisted of college students instructed to deny knowledge of learned material. One task consisted of a yes/no recognition task. The results indicated that the patients resembled the simulators in responding significantly slower to words learned in another identity compared to unlearned words, indicating that they were aware, but denied knowledge, of words learned in another identity. The second task consisted of a forced choice recognition task. In this task, veritable amnesia would show up as the tendency to respond with recognition $50 \%$ of the time (i.e. indicating chance). Two patients were tested, and one recognized $0 \%$ and the other $33 \%$ of the words learned by another identity. The authors concluded the first patient systematically avoided material learned by the other identity, while the result of the second patient did not differ significantly from chance.

In contrast, Eich and colleagues (1997) did not find evidence of malingering on a picture fragment completion task. One identity was shown cards representing objects in numerical sequence, i.e. from least to most detailed. Subsequently, another identity was shown the same cards and asked to name the object as soon as possible. The score equalled the number of cards that had to be seen before the object could be identified. Simulators, consisting of mentalhealth professionals, were able to simulate interidentity amnesia, indicating that they tried to act as if they had not seen a given object before, when in fact they had. Patients, however, achieved comparable priming scores to controls. The authors concluded that inter-identity amnesia does not seem to be simply a matter of response suppression.
Rendering a final conclusion difficult to draw, these studies suffered from small patient samples ( $n=4$ and $n=7)$ and a lack of a truly amnesic control group, be it either a patient control group suffering from organic amnesia or a normal control group consisting of participants who are 'amnesic' in the sense of not having been shown the test material.

The present study was specifically aimed at detecting simulation of inter-identity amnesia in DID by the inclusion of a task on which simulation was relatively easy. A relatively large patient sample of 22 patients was included. Moreover, simulation was examined more systematically than in previous studies by including three control groups: a normal control group with no amnesia receiving standard 'remember' instructions, a second control group instructed to simulate inter-identity amnesia, and a 'guessor' group that was never exposed to the stimulus material required to be remembered. Simulation was examined using two different methods. First, we determined the rate of incorrect answers. In addition, the specific simulation strategy used was examined by providing subjects with a range of answer alternatives that varied in degree of disagreement with the correct answer and determining whether plausible or implausible answer alternatives were selected. Following Martin et al. (1998), a probability-ofselection value was determined for each answer alternative by independent raters, after which summed probability-of-selection scores were determined for patient and control groups.

\section{METHOD}

\section{Subjects}

Twenty-two DID patients participated. They were recruited from 18 treatment settings (i.e. out-patient clinics and private practices) in The Netherlands and Belgium by asking clinicians to invite patients to participate. Nine patients had also participated in our previous experiments of inter-identity amnesia (Huntjens et al. 2002, 2003). Therapists were asked to confirm that patients met the following conditions for participation: (1) The DID diagnosis was made by administration of the Structured Clinical Interview for DSM-IV Dissociative Disorders (SCID-D; Steinberg, 1993); (2) at least one of the identities was completely amnesic for the 
events experienced by the other participating identity during the experiment; (3) identities were able to perform the tasks without interference of other identities; (4) they were able to perform the tasks without spontaneous switches to other identities; (5) they were all able to switch between identities on request. The mean number of years since diagnosis of DID for patients in the present sample was 6 years and DID was always the main reason for patients to be in treatment. Twelve patients reported one or more prior diagnoses: major depressive disorder $(n=6)$, borderline personality disorder $(n=4)$, post-traumatic stress disorder $(n=3)$, anorexia nervosa $(n=3)$, schizophrenia $(n=3)$, dissociative disorder not otherwise specified $(n=2)$, epilepsy $(n=1)$, obsessive-compulsive disorder $(n=1)$, personality disorder not otherwise specified $(n=1)$, bipolar disorder $(n=1)$, and avoidant personality disorder $(n=1)$. Seven patients reported present co-morbid disorders: major depressive disorder $(n=2)$, post-traumatic stress disorder $(n=2)$, anorexia nervosa $(n=1)$, obsessive-compulsive disorder $(n=1)$, bipolar disorder $(n=1)$, personality disorder not otherwise specified $(n=1)$, and avoidant personality disorder $(n=1)$.

Seventy-five female non-psychiatric control participants participated. They were community volunteers recruited by advertisement in a local newspaper and received a small payment. Subjects reporting visual, memory, or attention problems were excluded from participation, as well as subjects who were currently receiving psychiatric treatment.

The DID patient and the control groups were matched as closely as possible on age and education. Control participants were randomly assigned either to the normal control group, simulating group, or 'guessor' group, the latter functioning as an amnesic group. Approximately 1 week before the experiment, participants in the simulating group were given information about DID and were told that critics argued that the disorder may be iatrogenic. They were shown a documentary and given written information about DID and were subsequently asked to make up an imaginary, amnesic identity and supply detailed characteristics of this identity (for the exact procedure used see Silberman et al. 1985). Examination of the completed data sheets confirmed that participants had spent considerable effort inventing an identity. Finally, they were asked to practice during the week preceding the test in switching to their 'identity' and taking on its state of mind. Written informed consent was obtained for all subjects, and the study was approved by the local ethical review board.

\section{Materials and procedure}

Patients were informed that the aim of the study was to understand more about the memory problems often reported by patients with DID. They self-selected two identities that would participate in the experiment. In session 1, patients were asked to complete the Logical Memory - Story A (LM; maximum score 25) and Visual Reproduction (VR; maximum score 41) immediate recall tests from the Wechsler Memory Scale - Revised (WMS-R; Wechsler, 1987) in one identity state. A 30-min interval followed, after which patients were requested to switch to their amnesic identity. When the patient confirmed the presence of the second identity, this identity was asked whether she/he knew anything about the learning episode, i.e. about the general procedure followed and/or the material studied. In session 2 , the patients were informed that the other participating identity had heard a story and had been shown several drawn figures and had performed a recall test. Finally, they were asked to recall all they knew about the story and the figures that had been presented, i.e. they performed the LM and VR delayed recall tests. They were then presented with the critical test, a multiple-choice recognition test, consisting of 10 questions for the LM story, each asking about a particular story detail and offering three possible choices (Iverson \& Franzen, 1996) and five separate multiple-choice items for the VR, in which the original visual stimulus was presented along with four foils (E. Kaplan, unpublished observations). The recognition score was determined by summing the answers to the LM and VR recognition questions resulting in a maximum score of 15 .

Simulators performed the immediate recall tests in their normal identity state and the delayed recall and recognition test after having switched to their imagined 'amnesic' identity. Before 'switching' to their other identity, they were instructed to pretend in their amnesic 
Table 1. Age, Education, Dissociative Experiences Scale (DES) and Creative Experiences Questionnaire (CEQ) scores, Logical Memory (LM) and Visual Reproduction (VR) immediate and delayed recall scores, recognition scores, and summed probability-of-selection scores for DID patients $(n=19)$, controls $(n=25)$, simulators $(n=25)$, and guessors $(n=25)$

\begin{tabular}{|c|c|c|c|c|}
\hline & DID patients & Controls & Simulators & Guessors \\
\hline Age $(y r)$ & $38 \cdot 68(8 \cdot 59)$ & $35 \cdot 80(8 \cdot 59)$ & $36 \cdot 72(7 \cdot 88)$ & $37 \cdot 36(9 \cdot 16)$ \\
\hline Education (yr) & $5 \cdot 42(1 \cdot 26)$ & $5 \cdot 60(1 \cdot 00)$ & $5.68(1.18)$ & $5.44(0.92)$ \\
\hline DES & $55 \cdot 20(15 \cdot 02)$ & $9 \cdot 50(6 \cdot 28)$ & $8 \cdot 11(4 \cdot 71)$ & $10 \cdot 36(4 \cdot 62)$ \\
\hline CEQ & $9 \cdot 92(4 \cdot 38)$ & $6 \cdot 36(3 \cdot 34)$ & $6 \cdot 64(4 \cdot 02)$ & $5.52(2.92)$ \\
\hline LM - Immediate & $11.53(4 \cdot 86)$ & $15 \cdot 88(3 \cdot 47)$ & $14 \cdot 76(3 \cdot 57)$ & - \\
\hline LM - Delayed & 0 & $14 \cdot 88(3 \cdot 50)$ & 0 & - \\
\hline VR - Immediate & $33 \cdot 63(5 \cdot 18)$ & $36 \cdot 00(5 \cdot 31)$ & $34 \cdot 64(3 \cdot 70)$ & - \\
\hline VR - Delayed & 0 & $33 \cdot 64(5 \cdot 27)$ & 0 & - \\
\hline Recognition & $3 \cdot 11(1 \cdot 59)$ & $13 \cdot 28(1.46)$ & $1.88(1.59)$ & $4.56(1.83)$ \\
\hline SPS & $3 \cdot 71(1 \cdot 05)$ & $9 \cdot 22(0 \cdot 74)$ & $2 \cdot 74(1 \cdot 15)$ & $4 \cdot 47(1.08)$ \\
\hline
\end{tabular}

SPS, Summed probability-of-selection scores.

Standard deviations in parentheses. Education was assessed in categories ranging from 1 (low) to 7 (high) (Verhage, 1964).

identity to have no knowledge of the immediate recall testing whatsoever, i.e. to pretend no knowledge of having been read a story or having been shown drawn figures. Participants in the guessing group only performed the recognition task without being presented with the LM story or the VR figures, thus functioning as a true amnesic group. After the recognition memory task, all participants completed both the Dissociative Experiences Scale (DES; Carlson \& Putnam, 1993) and the Creative Experience Questionnaire (CEQ; Merckelbach et al. 2000).

Probability-of-selection values for each recognition item were determined in a separate control sample consisting of 12 mental health professionals and psychologists. The subjects were asked to rate the probability from 0.00 to 1.00 that each intra-item alternative would probably represent the correct alternative for each particular test item. For example, the first LM recognition item reads: 'Was the story about a man, woman, or animal?' The raters were asked to assign a probability value to each answer alternative summing to 1.00 (for example 0.25 for man, 0.70 for woman, and 0.05 for animal). The mean standard deviation for the LM ratings was 0.073 and for the VR ratings $0 \cdot 046$. Based on these scores, an average probability value for each alternative was calculated across the raters. We then assigned that value to each participant's chosen alternatives. Finally, a total probability-of-selection score was calculated for each subject by summing each of the 15 individual probability-of-selection values (10 from the LM and 5 from the VR recognition test).

\section{RESULTS}

Of the 22 DID patients tested, three patients reported, following their switch to identity 2 , knowledge of some elements of the learning phase. These patients were excluded from the results. The data thus pertain to 19 DID patients who subjectively reported complete one-way amnesia for the learning phase. All pairwise comparison procedures described were Bonferroni tests.

In Table 1, mean logical memory (LM) and visual reproduction (VR) immediate and delayed recall scores (guessors did not perform the recall tasks), total correct recognition scores, and summed probability-of-selection scores are presented across groups, as well as age, education, mean DES scores and total CEQ scores. ANOVAs revealed no significant differences between groups on age $(F=0.43, \mathrm{df}=3,90$, $p=0.73)$ and education $(F=0.31, \mathrm{df}=3,90$, $p=0 \cdot 82)$. Control participants did not show a pathological level of dissociation as measured by the DES. The control groups did not differ significantly on mean DES score $(F=1 \cdot 16$, $\mathrm{df}=2,72, p=0 \cdot 32)$, nor on the CEQ $(F=0 \cdot 71$, $\mathrm{df}=2,72, p=0 \cdot 49)$. Patients, on the other hand, differed significantly from normal controls both on the DES $(t=13 \cdot 75, \mathrm{df}=42, p<0.001)$ and the CEQ $(t=3 \cdot 06, \mathrm{df}=42, p<0 \cdot 01)$. 
As explained above, all participants except the guessors first completed immediate recall. Normal controls then proceeded with the delayed recall and recognition. Patients and simulators performed the delayed recall and recognition after their 'switch' to their amnesic identity. Guessors only performed the recognition test. Recall scores are presented to give an account of the participants' overall memory performance. An ANOVA on immediate LM (maximum score 25) excluding the guessor group revealed that the other groups differed significantly $(F=6 \cdot 92, \mathrm{df}=2,66, p<0 \cdot 01)$. DID patients scored significantly lower compared to normal controls $(p<0.01)$ and simulators $(p=0.03)$. Normal controls and simulators did not differ significantly $(p=0 \cdot 95)$. On immediate VR (maximum score 41), no significant differences between groups were found $(F=1 \cdot 39$, $\mathrm{df}=2,66, p=0 \cdot 26$ ).

Crucial for examining simulation strategies are the recognition scores. Two recognition measures were employed, the first being the rate of incorrect answers and the second being the plausibility of the answer alternative selected. As explained above, the rate of incorrect answers was determined by the total number of correct recognition items (with a maximum of 15). The plausibility of the answer alternative selected was determined by filling in average probability-of-selection values as provided by independent raters for the answer alternative chosen by the participant and summing the values across items.

An ANOVA on the total recognition scores revealed that DID patients, controls, simulators, and guessors differed significantly $(F=$ $247 \cdot 30, \mathrm{df}=3,90, p<0 \cdot 01)$ with controls scoring significantly higher than all other groups ( $p$ 's $<0 \cdot 01)$. The guessors' mean score indicates chance, since these participants were not shown the LM and VR stimuli. DID patients and simulators both scored significantly below the guessors (with $p<0.01$ for the difference between simulators and guessors and $p=0.03$ for the difference between patients and guessors). Both groups thus scored significantly below chance. Importantly, patients did not differ significantly from simulators $(p=0 \cdot 09)$. Both groups thus scored more incorrect answers than normal controls and scored even more incorrect answers than could be expected on a chance level, compared to the guessors who had no knowledge of the stimulus material at all.

On total summed probability-of-selection scores, the groups also differed significantly $(F=97.98, \mathrm{df}=3,90, p<0 \cdot 01)$. Again, normal controls performed significantly better than all other groups $(p$ 's $<0 \cdot 01)$. Their higher score reflects that normal controls selected more plausible answer alternatives. Again, the guessors' score can be taken as chance level, and yet again, the simulators scored significantly lower than guessors $(p<0 \cdot 01)$. Patients ended up scoring significantly higher compared to simulators $(p=0 \cdot 01)$, while not differing significantly from guessors $(p=0 \cdot 10)$. This indicates that simulators chose less plausible answer alternatives than could be expected on a chance performance. Their specific simulation strategy thus consisted of (1) often choosing incorrect answers in the recognition task, and (2) in the case of an incorrect answer, often choosing implausible answers. Patients were also characterized by often choosing incorrect answers. They were, however, not characterized by a strategy to choose implausible answer alternatives.

\section{DISCUSSION}

This study set out to systematically examine the simulation of inter-identity amnesia symptoms by DID patients. As mentioned previously, 19 patients reported complete inter-identity amnesia. Indeed, the patients' recall scores indicated no knowledge of the stimulus material learned in the other identity state. On the critical recognition test, however, patients behaved like simulators in scoring below chance, i.e. they relatively often provided incorrect answers, more often than the guessors who were really unfamiliar with the stimulus material. This indicates that patients used their knowledge of the correct answer in determining their incorrect given answer.

Interestingly, patients did not resemble simulators in the specific simulation strategy used, i.e. they did not choose very implausible answer alternatives as did the simulators. For example, in response to the question 'Was the story about a man, woman, or animal', patients, as well as simulators and guessors, relatively often responded with an incorrect answer in contrast to normal controls who responded with the 
correct answer 'woman', Simulators relatively often gave the implausible answer 'animal', while patients as well as guessors chose the more plausible alternative 'man'. While patients thus used their knowledge of the correct answer in determining their given answer, they were not characterized by the specific simulating strategy utilized by the simulators in this study, who chose implausible answer alternatives compared to normal controls and guessors.

One could argue that the differing results of patients and simulators, i.e. patients choosing more plausible answer alternatives compared to simulators, can be taken to indicate patients are more sophisticated malingerers than the simulators used in this study. That is, patients may have chosen 'near miss' answer alternatives instead of the 'obvious' malingering alternatives. While this explanation cannot be ruled out, we find it unlikely, because the simulators were instructed carefully to simulate both DID and inter-identity amnesia. Prior to 'switching' to their other identity, it was ensured they understood all instructions, and during debriefing, it was checked whether they had succeeded in following the instructions. They were also asked to describe their personal dissimulation strategy. Several different strategies were mentioned: choosing very improbable answers, choosing near misses, choosing randomly, and choosing alternatives consistent with their imagined identity (i.e. current mood state or preferences).

Importantly, the similarities in behaviour between simulators and patients, both performing below chance on recognition, do not necessarily indicate identical causal mechanisms for the observed behaviour. While feigned behaviour is characterized by intentional production of symptoms motivated by external incentives like economic gain or avoiding legal responsibility, the motivation of patients for the production of amnesia symptoms may also be to assume the sick role, as in factitious disorder. Moreover, DID patients may not be intentionally simulating, but instead suffer from so-called meta-memory problems, i.e. they are truly convinced of not knowing what happens when another identity is in control of their behaviour (Kindt \& van den Hout, 2003). Meta-memory problems may lead patients not to acknowledge correctly retrieved material, which is believed to 'belong' to other identities, or indeed choose an incorrect answer alternative following their belief that the correct answer alternative cannot be known if the material that one is tested for was learned by another identity. The disorder may thus be characterized by self-delusion instead of deliberate pretence. Note that other psychological conditions are characterized by patient cognitions that are incomprehensible to others, like an anorectic patient who believes her body to be fat despite being obviously underweight.

The finding of an absence of objective evidence for self-reported inter-identity amnesia coincides with several other recent studies of inter-identity amnesia in DID (Silberman et al. 1985; Eich et al. 1997; Allen \& Movius, 2000; Huntjens et al. 2002, 2003, 2005; Elzinga et al. 2003). What are the implications of these findings for the diagnostic status of DID? With caution, we suggest that should inter-identity amnesia be considered a prerequisite for the diagnosis, the results presented here pose serious problems to the validity of the disorder. Alternatively, the diagnostic criteria could be changed to exclude amnesia, as in the DSMIII-R definition of multiple personality disorder. This, however, would result in the blurring of the diagnostic distinctions between DID and associated disorders like post-traumatic stress disorder and borderline personality disorder. The results of this study do not, however, speak against symptoms of depersonalization, derealization, and identity confusion which are prevalent in these patients. Moreover, the results do not raise doubts about the veracity of the reports of physical and sexual abuse often made by DID patients. One could speculate about the causal link between childhood abuse and meta-memory problems. To make sense of the conflicting situation of childhood sexual abuse (i.e. the adult as caregiver and as abuser), a young child may come to experience the self as consisting of different parts, states, or identities answering the different situational demands. While the experiences are inevitably encoded in memory, the child may imagine the abuse as not happening to the self to avoid the full realization and confrontation of the pain and incomprehension of the abuse.

In conclusion, the task proved successful in discriminating between normal control subjects, 
'amnesics' in the form of guessors who were not exposed to the test material, and simulating controls. While 19 patients reported no knowledge whatsoever of the material learned in another identity state, they did use their knowledge of the test material learned in another identity state in determining their answers (i.e. relatively often choosing incorrect answers). We found DID patients not to be characterized, however, by a well-thought-out simulating behaviour style, as indicated by the differences found between them and the simulators included in the study. While simulators were instructed to intentionally feign amnesia, we speculate the patients' results may be based on incorrect beliefs about their own memory functioning, being convinced of the inability to retrieve material learned in another identity state.

\section{ACKNOWLEDGEMENTS}

Albert Postma was supported by a grant from The Netherlands Organization for Fundamental Research (NWO, No. 440-20-000).

\section{DECLARATION OF INTEREST}

None.

\section{REFERENCES}

Allen, J. B. \& Movius, H. L. (2000). The objective assessment of amnesia in dissociative identity disorder using event-related potentials. International Journal of Psychophysiology 38, 21-41.

Carlson, E. B. \& Putnam, F. W. (1993). An update on the dissociative experiences scale. Dissociation 6, 16-27.

Dorahy, M. J. \& Lewis, C. A. (2002). Dissociative identity disorder in Northern Ireland: a survey of attitudes and experience among clinical psychologists and psychiatrists. Journal of Nervous and Mental Disease 190, 707-710.

Eich, E., Macaulay, D., Loewenstein, R. J. \& Dihle, P. H. (1997). Implicit memory, interpersonality amnesia, and dissociative identity disorder: Comparing patients with simulators. In Recollections of Trauma: Scientific Research and Clinical Practice (ed. J. D. Read and D. S. Lindsay), pp. 469-474. Plenum Press: New York

Elzinga, B. M., Phaf, R. H., Ardon, A. M. \& Van Dyck, R. (2003). Directed forgetting between, but not within, dissociative personality states. Journal of Abnormal Psychology 112, 237-243.

Huntjens, R. J. C., Postma, A., Hamaker, E. L., Woertman, L., Van der Hart, O. \& Peters, M. L. (2002). Perceptual and conceptual priming in patients with dissociative identity disorder. Memory \& Cognition 30, 1033-1043.

Huntjens, R. J. C., Postma, A., Peters, M. L., Woertman, L., Effting, M. \& Van der Hart, O. (2005). Transfer of newly acquired stimulus valence between identities in dissociative identity disorder. Behaviour Research and Therapy 43, 243-255.

Huntjens, R. J. C., Postma, A., Peters, M., Woertman, L. \& Van der Hart, O. (2003). Inter-identity amnesia for neutral, episodic information in dissociative identity disorder. Journal of Abnormal Psychology 112, 290-297.

Iverson, G. L. \& Franzen, M. D. (1996). Using multiple objective memory procedures to detect simulated malingering. Journal of Clinical and Experimental Neuropsychology 18, 38-51.

Kindt, M. \& Van den Hout, M. (2003). Dissociation and memory fragmentation: Experimental effects on meta-memory but not on actual memory performance. Behaviour Research and Therapy 41, 167-178.

Lalonde, J. K., Hudson, J. I., Gigante, R. A. \& Pope, H. G. (2001). Canadian and American psychiatrists' attitudes toward dissociative disorders diagnoses. Canadian Journal of Psychiatry 46, 407-412.

Lilienfeld, S. O., Lynn, S. J., Kirsch, I., Chaves, J. F., Sarbin, T. R., Ganaway, G. K. \& Powell, R. A. (1999). Dissociative identity disorder and the sociocognitive model: Recalling the lessons of the past. Psychological Bulletin 125, 507-523.

Martin, R. C., Franzen, M. D. \& Orey, S. (1998). Magnitude of error as a strategy to detect feigned memory impairment. Clinical Neuropsychology 12, 84-91.

Merckelbach, H., Rassin, E. \& Muris, P. (2000). Dissociation, schizotypy, and fantasy proneness in undergraduate students. Journal of Nervous and Mental Disease 188, 428-431.

Pope, H. G., Oliva, P. S., Hudson, J. I., Bodkin, J. A. \& Gruber, A. J. (1999). Attitudes towards DSM-IV dissociative disorders diagnoses among board-certified American psychiatrists. American Journal of Psychiatry 156, 321-323.

Silberman, E. K., Putnam, F. W., Weingartner, H., Braun, B. G. \& Post, R. M. (1985). Dissociative states in multiple personality disorder: a quantitative study. Psychiatry Research 15, 253260.

Spanos, N. P. (1996). Multiple Identities and False Memories. A Sociocognitive Perspective. American Psychological Association: Washington, DC.

Steinberg, M. M. D. (1993). Structured Clinical Interview for DSM-IV Dissociative Disorders (SCID-D). American Psychiatric Press: Washington, DC.

Verhage, F. (1964). Intelligence and age: study with Dutch people from age 12 to 77 [in Dutch]. Van Gorcum: Assen, The Netherlands.

Wechsler, D. (1987). Wechsler Memory Scale-Revised. The Psychological Corporation: San Antonio, TX. 